See discussions, stats, and author profiles for this publication at: https://www.researchgate.net/publication/338780744

\title{
Factors influencing the implementation of Epilepsy Specialist Nurse Role: using the Consolidation Framework for Implementation Research
}

Article in Journal of Clinical Nursing • January 2020

DOI: 10.1111/jocn.15197

\section{CITATIONS}

4

6 authors, including:

Agnes Higgins

Trinity College Dublin

201 PUBLICATIONS 2,820 CITATIONS

SEE PROFILE

Carmel Downes

Trinity College Dublin

44 PUBLICATIONS 441 CITATIONS

SEE PROFILE

Some of the authors of this publication are also working on these related projects:

Project MidU study View project

Project Towards a Full Life - GENIO View project
B. Rebecca Murphy

National University of Ireland, Maynooth

40 PUBLICATIONS 298 CITATIONS

SEE PROFILE

Jarlath David Varley

Royal College of Surgeons in Ireland

25 PUBLICATIONS 194 CITATIONS

SEE PROFILE 
Higgins A, Murphy R, Downes, C, Varley, J., Begley C, Elliott N (2020) Factors influencing the implementation of Epilepsy Specialist Nurse Role: using the Consolidation Framework for Implementation Research Journal of Clinical Nursing doi:

\subsection{1/JOCN.15197}

Please note this edition may not correspond exactly to the published paper.

Factors influencing the implementation of Epilepsy Specialist Nurse Role: using the Consolidation Framework for Implementation Research

\section{Short Heading: Implementation of Epilepsy Specialist Nurse Role} ABSTRACT

Background: Research to support the added value of including Epilepsy Specialist Nurses as members of the multidisciplinary team is developing, yet little information exists on factors influencing the translation of these roles into practice.

Aim: To describe the enabling and inhibiting factors to the implementation of the Epilepsy Nurse Specialist role in the Republic of Ireland.

Methods: A qualitative design involving semi-structure interviews, observation and analysis of documents, such as portfolios was used. The sample included 12 epilepsy specialist nurses, 24 multidisciplinary team members, and 35 individuals with epilepsy and family members. Data were analysed using the Consolidation Framework for Implementation Research. Reporting rigor is demonstrated using the COREQ checklist (See Supplementary File 1). Results: While there was overwhelming support for the role, barriers and enablers were identified across all domains of the Consolidation Framework for Implementation Research. Enablers included national policies and guidelines, leadership from senior nursing and medical colleagues, climate of learning and mentorship, networking opportunities, 
infrastructural supports, and competence of ESNs. Barriers included the limited consideration of service expansion and the increasingly complex nature of clinical cases on workload capacity. Deficits in infrastructural supports, challenges in relation to role preparation, role implementation and role responsibility, including concerns around lone practitioner models and concerns that the role was a cost saving measure, also emerged as potential barriers to future sustainability.

Conclusion: The Consolidation Framework for Implementation Research offers researchers a pragmatic typology for analysing interrelationships between enabling and inhibiting factors that impact implementation of advanced practice roles, across different evidence sources, disciplines and boundaries.

Relevance to clinical practice: In order to secure role sustainability, managers need to address the rate of service expansion, models of role development, deficits in supports and perceived motivations for role development on the quality, acceptability, and sustainability of services provided.

Keywords: implementation; factors influencing, sustainability; role implementation, Epilepsy Specialist Nurse; advanced practitioner.

\section{What does the paper contribute to the wider global clinical community?}

- This is the first study that used an implementation theory to identify factors influencing implementation of advanced practice roles.

- The study adds to the limited body of research into contextual and mediating factors that influence role implementation of Epilepsy Specialist Nurses Role. 
- The paper highlight a number of issues that negatively impact role sustainability, such as: rate of service expansion, model of role development, deficits in supports and perceptions of individuals involved.

- The study provides evidence that the Consolidation Framework for Implementation Research is a useful typology to guide the exploration of implementation contexts and processes.

\section{INTRODUCTION}

Specialist and advanced nursing roles have developed in many countries. In many situations, these roles are seen as a solution to some of the challenges healthcare services are facing, in relation to accessing efficient and timely care that is person-centred, empowering and health promoting (Lowe et al., 2012; Plager and Conger, 2007). However, the process of implementing and sustaining these roles is challenging and complex, as not only does the process involve interdependent interactions within and across disciplines, teams, and service units, but there is a need to take account of patient perspectives and local context. This study uses the Consolidation Framework for Implementation Research (CFIR) (Damschroder et al., 2009) to explore factors that influence the implementation of Epilepsy Specialist Nurse [ESN] role in the Republic of Ireland.

\section{BACKGROUND}

Epilepsy is a chronic neurological disease characterised by recurring seizures with a prevalence estimated to be between 5-10 per 1,000 persons (National Institute for Health and Care Excellence (NICE), 2012). While untreated epilepsy can impact mortality, health morbidities and quality of life, with timely and appropriate care the vast majority of people 
with epilepsy (PWE) will experience long-term remission (NICE, 2012). Today, the inclusion of an epilepsy specialist nurse (ESN) is recognised as an integral part of the epilepsy multidisciplinary care team and while the ESN role has existed in the UK since 1988 (Goodwin et al., 2004), there is limited research on the factors that influence role implementation and role integration. The studies that exist tend to focus on describing the ESN role (Higgins et al., 2018a, 2019a, 2019b; Hopkins and Irvine, 2012) or charting the impact of the role on patient and family outcomes (Bradley et al., 2016;; Higgins et al., 2018b; Kengne et al., 2008;; Noble et al., 2013; Pfäfflin et al., 2016;). While these studies provide important data on the added value of such roles, they tell us little about the factors that help or hinder the translation of these roles into practice. Barriers and enablers can occur at various levels of health care; including the patient, provider, organisational and policy level (Damschroder et al., 2009). In areas of nursing other than epilepsy, factors identified as supportive for specialist and advanced practice roles were support from the disciplines of medicine and nursing; the provision of structural and educational supports; and personal attributes of the practitioner (Begley et al., 2010; Casey et al 2019., Delamaire and Lafortune, 2010; DiCenso et al., 2010; Elliott et al, 2016; Higgins et al., 2014; Keating et al., 2010; Kilpatrick et al., 2012, 2013; Lindblad et al, 2010; Pulcini et al., 2010; ). In the context of the ESN role in the UK, Hopkins et al. (2010) found that while there was lots of support within the multidisciplinary team for the role, when staff shortages occurred in other areas of the service the ESNs had to fill the gap and work in non-specialist roles. Similarly, while doctors were supportive of ESNs having prescribing authority if they were working in 'isolation', however, if doctors and nurses were worked in close proximity there was some resistance to their prescribing role (Hopkins et al., 2010). 
In the Republic of Ireland, up to 2013 ESN posts were being developed in an adhoc manner at local level and subsequent to this epilepsy services were rearranged under the National Epilepsy Care Programme (NECP), which had the stated objective of addressing deficits in the quality of epilepsy care. As part of this government funded drive the NECP advocated that every Person with Epilepsy (PWE) have the opportunity to avail of an ESN at a registered advanced nurse practitioner (RANP) level (HSE, 2014). An ANP is an autonomous nurse, educated to a Master degree level, with four elements to the role; namely clinical, leadership, education, and research (NCNM, 2008). As implementation is a 'critical gateway between an organisation's decision to adopt an intervention and the routine use of that intervention in practice' (Damschoder et al., 2009:3), to enhance the quality and efficacy of implementation of future roles there is a need for evidence-based information on the factors that influence the implementation process. To address this issue, the aim of this paper is to describe the enabling and inhibiting factors to the implementation of the ESN role in the Republic of Ireland.

\section{METHODS}

To meet the research aim, the study was designed as an exploratory, descriptive qualitative study, which utilised data from interviews, observation and documents. COREQ checklist was used for this paper (See Supplementary File 1).

\section{Study sites}

Information-oriented sampling, was used to select five hospital based epilepsy services which employed ESNs as part of the MDT. Four services provided care to adults and one provided care to children. To ensure geographic spread and urban and rural divide the services represented different health care areas in the Republic of Ireland. They also varied in the 
number of ESNs employed within the team, with some employing one ESN while others had multiple ESNs, with a mixture of Registered ANPs, Candidate ANPs and Clinical Nurse Specialists.

The Director of Nursing and Medical Consultant Permission gave permission to access each site following written communication and a telephone conversation with a member of the research team.

\section{Recruitment}

A member of the research team visited each site and made a presentation about the proposed study to ESN, medical consultants and other stakeholders. Once potential participants had at least one week to deliberate on the verbal and written information provided, a member of the research team commenced recruitment. ESNs and members of the multidisciplinary team (MDT) were purposively sampled. PWE and family members were recruited through convenience sampling by the ESNs. No person invited refused to participate.

\section{Data collection}

Data were collected using multiple methods including: semi-structured, audio recorded interviews (one to one and focus group), non-participant observation and documentation (Table 1). Interview schedules were developed by the team to guide data collection, and included questions about barriers to and enablers of implementation of the role. The observation involved shadowing each ESN, on at least two occasions, and recording fieldnotes on the context of the role and issues affecting or influencing the implementation process (Table 2). ESNs were also requested to collect and make available documentary evidence, such as portfolios, networking/educational activities, and research/audit activity. 
Two experienced researchers and nurses (AH and JV) collected the data between late 2013 and 2016, within the hospital sites.

\section{Insert table 1: Data collection methods and sources \\ Insert table 2: Interview and observation schedule}

\section{Ethical considerations}

The university's Research Ethics Committee and the ethics committee at all sites granted approval. To ensure informed consent participants were given written and verbal information about the study and were required to provide written and verbal consent.

\section{Data analysis}

Data from all sources (interview, observations and documents) were inputted into NVivo and analysed using the Consolidation Framework for Implementation Research (CFIR)

(Damschroder et al., 2009). The CFIR is a meta-theoretical framework designed to guide the appraisal of implementation contexts, including the factors that might influence implementation. The framework consists of the five domains: outer setting, inner setting, intervention characteristics, individual characteristics and implementation process. The authors acknowledge that while the framework identifies discrete domains and specifies constructs within each domain to be explored, in reality the domains interact with each other in 'rich and complex ways' (Damschroder et al., 2009|:3). Table 3 provides an overview of the domains and the constructs associated with each domain.

Insert table 3 Overview of the Consolidation Framework for Implementation Research 
In this study analysis was completed by three team members (AH, NE and RM), and the final coding was agreed by consensus ( $\mathrm{AH}$ and $\mathrm{RM}$ ), thus ensuring consistency in data interpretation.

\section{Sample}

The sample consisted of ESNs ( $\mathrm{n}=12)$, people with epilepsy (PWE) $(\mathrm{N}=21)$, family members $(n=14)$ and key stakeholders (5 Directors of Nursing/Assistant Directors of Nursing, 6 Medical doctors at consultant level, 2 Clinical Nurse Managers, and 11 Allied Professionals who had direct contact with the ESNs). The ESN sample was all female and although they were working in the current epilepsy post for a number of years (Mean $=5.42$ years, Range 2- 21 years), at the time of the study they were working within the NECP role description and guidelines. Two participants had achieved their RANP qualification, five had recently commenced the ANP qualification (cANPs) and five were working as clinical nurse specialists (CNSs). In addition to holding a number of qualification they all had specialist education in the area of epilepsy care. Table 4 provides further detail.

\section{Insert Table 4 Demographic profile of ESNs}

\section{RESULTS}


Barriers and enablers were identified within all five domains of the CFIR. Table 5 provides data to support findings in each domain.

\section{Outer setting (Domain A)}

The outer setting comprises the economic, political and social context in which an organisation inhabits and includes such things as policies and incentives to influence implementation, organisational awareness of patient needs, and extent to which the organisation is networked with other organisations (Damschroder et al., 2009). In the context of this study policies that facilitated implementation included the national policy in relation to Epilepsy Care (HSE, 2014) and national guidelines on implementation of nurse specialist posts (NCNM, 2008). The National Epilepsy Care Programme ((NECP) HSE, 2014) identified national deficits in service delivery which informed its recommendation that every PWE should have the opportunity to avail of an ESN, at an advanced practitioner level, with a real-time, electronic patient record (EPR) shared across the services that provide epilepsy care. In addition, to mapping out what an interconnected service should look like, it included a clearly defined strategic role for the ESN, funding for new ESN posts at ANP level, including supports in the form of study leave and funding, as well as providing guidelines and Standard Operating Procedures (SOPs) for the provision of care to PWE (A1- A3).

The national document guiding development and accreditation of advanced nurse practitioners was also critical (NCNM, 2008). This document outlines the core concepts underpinning advanced roles, alongside a delineation of a site preparation and approval process (NCNM, 2008). In addition to providing clarity around the ANP role, the document outlined the required preparation process for an ANP, and stipulated the need for the 
development of local policies and guidelines, in collaboration with medical consultants and senior nurses (A4). While the document, in this context, was an enabler it was also perceived as a barrier. Within the NCNM policy document, it is the clinical site and post rather than the post holder that is approved (NCNM, 2008); consequently, there is a lack of transferability of the Registered Advanced Nurse Practitioner (RANP) post across organisations. The inability of ESNs to transfer their post and seek employment in a new organisation was identified as a potential barrier to attracting suitable people to ESN posts, thus impacting future sustainability (A5). In addition, like a double edged sword, the demands and intensive commitment required by ESNs to achieve all of the activities required under the guidance document to become an accredited ANP, was seen as a potential barrier to attracting future nurses into the ESN role (A6).

Networking opportunities with the Nursing and Midwifery Board of Ireland (NMBI) (A7), national and international epilepsy interest groups, as well as attending epilepsy conferences (A8-9), were key supports in enabling the ESNs to develop their role and keep abreast of future trends and developments in epilepsy care. In addition to these boundary-spanning activities the RANPs in epilepsy care provided support to less experienced ESNs and candidate ANPs in other services during the implementation phase. Besides providing advice on role development they mentored them as they initiated new nurse-led epilepsy services and implemented national epilepsy policies, including the EPR (A10-A12).

\section{Inner setting (Domain B)}

The inner setting includes characteristics of the organisation in which the intervention occurs, and includes issues such as leadership engagement, the learning climate, resources available 
and nature and quality of communication within the organisation (Damschroder et al., 2009). From a leadership engagement perspective, support from epilepsy and neurology medical consultants was paramount to the development and assimilation of the ESN posts. From a governance perspective, the involvement of medical consultants in the development of local protocols and guidelines, supported ESN's to have their scope of practice was accepted by other disciplines. Although one site did indicate ongoing challenges with regards allied health professionals' acceptance of referrals from ESNs, in the majority of situations, this collaboration with medical consultants minimised opposition to the scope of practice of ESNs being extending (B1-B2). Leadership from the Directors of Nursing (DoNs) and other senior nurses was just as essential to the integration of the posts. As executive managers, DoNs played a critical role in brokering support for ESN roles from local nursing development units and nurses at different grades (Assistant DoN to staff nurse) (B3-B4).

A strong climate of learning and mentorship within the team was appraised to influence change positively. Medical consultants provided ESNs with clinical supervision and mentorship, as they developed advanced competencies in epilepsy care, and nurtured their confidence to grow as autonomous clinical practitioners (B5-B7). However, medical consultants did highlight the ongoing challenge they were experiencing in carving out sufficient time to supervise ESNs in their clinical skill development, whilst simultaneously maintaining their own clinical caseload (B8). To support ESNs in their learning and the development of their clinical expertise, DoNs were critical in securing educational resources such as study leave/ protected study time (B9). In addition to support from medical consultants and senior nursing, both RANPs and non-epilepsy RANPs within the service 
offered advice and assistance to the ESNs about the clinical aspects of their role and site preparation (B10-B11).

While all ESNs were using evidence and conducting audits to inform developments in practice (Reference inserted after review), when it came to the research dimension of their role there was more heterogeneity. In MDTs where there was a culture of undertaking research the ESNs were beginning to participate in MDT research (B12-B13). In contrast, in two services, where research was less of a focus within the MDT, senior medical personnel were of the view that this was negatively impacting on the ESNs engaging in research (B14).

The availability of infrastructural resources was both an enabler and a barrier to the ESNs' role. When ESNs had administrative personnel and information technology (IT) available, they had extra time to attend to patient need and focus on other facets of their role, such as auditing and building knowledge capacity of health practitioners in relation to epilepsy. However, in cases where there was a lack of administrative personnel, ESNs' spent retrieving patients' charts from records department (if a PEW's health record was not already on the EPR), delivering forms for tests, sending out appointment letters and filing patient information (B15-B16). Inserting patient information into the EPR also consumed significant time (B17). In addition, the physical accommodation available to some ESNs was unsuitable to deliver care, as they often shared offices, delivered services in confined conditions, and spent time locating a private space for consultations with PWE and their family (B18-B19). The third resource issue that influenced the role was ease of access to information and knowledge. The dearth of IT support and deficiencies in the harmonisation of the EPR within the technology systems in use not only added workload and consumed time (B20-B21), but in 
certain services, easy access to online library resources such as specialist epilepsy

publications was not available, which limited the ESN's ability to source timely evidencebased information (B22).

\section{Characteristics of the intervention (Domain C)}

Intervention characteristics refer to issues such as stakeholder perception of the legitimacy of the source of the intervention, validity of the evidence supporting the intervention, and complexity of the intervention (Damschroder et al., 2009). While all participants viewed the source of the intervention as credible and cited evidence of the benefits of the role to PWE and families (C1-C6), the complexity (model, scope and adaptability) of the intervention emerged as a challenge. In services that adopted a lone practitioner model for the intervention, as opposed to a multiple practitioner model, challenges were encountered. Within the lone practitioner model, large caseloads and lack of time hindered the ESNs' ability to advance the development of clinical services, and engage with the leadership and research aspects of the role. Moreover, services that operated a lone practitioner model risked having gaps in service delivery due to the absence of a replacement for the ESN during leave (holiday, sick or other leave) (C7-C8). ESNs working as lone practitioners also mentioned feeling isolated within their own service as they were the 'innovator' and 'lone champion' for the advanced practice epilepsy role (C9).

Although the ESNs were attaining substantial success in increasing the number and types of epilepsy services available (Higgins et al 2018a, 2019a), this was increasing the complexity of the profile of the PWE they were meeting, and resulting in multifaceted inter-agency working. The demand of an increasingly complex clinical workload was further exacerbated 
by the need for involvement of services beyond the ESN's remit (e.g. obtaining bed for emergency admission or securing service/therapy for mental health problems), which were not always obtainable in a timely fashion (C10). The prioritisation of meeting the ever increasing clinical demands also acted as a barrier to the ESNs pursuing the core research dimensions of the role (C11- C13).

While some supports were given, in the form of study leave, the ESNs, who were candidate ANPs and still on the ANP pathway, were also challenged to balance the demands of completing a Master's degree level of education, preparing documentation to achieve accreditation and site approval whilst simultaneously managing their clinical caseload, developing epilepsy services guidelines and policies for practice (C14-C15).

A particular challenge experienced by some ESNs was the complexity of their work locations. Some had employment contracts with one organisation, yet were advancing the development and delivery of services in different hospitals and organisations. This left some ESNs feeling they were constantly trying to accommodate two different hospital approaches and management styles (C16).

\section{Characteristics of individuals involved (Domain D)}

This domain addresses the individual provider of the intervention/innovation and is concerned with the person's knowledge and beliefs about the intervention, the value they place on the intervention as well as their beliefs about their capabilities to execute the intervention (Damschroder et al., 2009). Overall the ESNs were very positive and enthusiastic about the innovation and were positive about their ability to perform or acquire 
the skills necessary to perform all aspects their role. Evidence indicated that they had availed of a number of academic programmes and educational opportunities to advance their knowledge and skills in their specialist area of epilepsy. The skill and competence of the ESNs was an enabler to implementation and acceptance of the role. The very fact that they were perceived by MDT members as being confident clinical decision-makers who were knowledgeable about epilepsy, and knew how to navigate the complex health environment (D1-D5), generated confidence in senior medical personnel about the role. They were perceived to be innovative, creative and committed to their professional development as well as developing quality epilepsy services (D6-D8). The MDT, PWE and family members also commented on their humanness, dedication and commitment to patient-centered practice (D9-D11) which again generated enthusiasm and reinforced beliefs among the wider community that they could perform the role to a high standard. Although some ESNs were becoming more involved in research they were of the view that their lack of knowledge and skills in the conduct of systematic literature reviews, data analysis and the funding of research was a barrier to them developing and implementing the research aspect of their role (D12). While autonomy was seen as an enabler and a factor that attracted people to the role, some participants also viewed it as a barrier, commenting on the reticence of experienced nurses to assume the responsibility connected to the ANP role because of the perceived additional stress (D13-D14).

\section{Implementation process (Domain E)}

The implementation domain takes account of the extent an implementation plan or method for putting an intervention into place has been developed in advance and the quality of the plan or method (Damschroder et al., 2009). All stakeholders agreed that the ESNs had 
achieved considerable success in executing the aims and plan outlined in the NECP, and were developing new nurse-led services, outreach services and improving continuity of care and access to services. However, participants were concerned that what they perceived as an absence of stated parameters within the Programme, on clinical workload and service expansion, had resulted in ESNs arriving at a crucial tipping point wherein service needs was greater than the resources available (E1-E2). Potential consequences identified were an increased risk of ESN burnout (E3), detrimental impact on the quality of the service provided (E4), protracted or delayed expansion of new epilepsy services (E5) and lack of time to develop a long-term vision and plan for services (E6-E7).

Planning involves taking account of all stakeholders' needs and perspectives including the recipients of the intervention, which in this case is the PWE and their family members. Although the data indicated that as time progressed the majority of PWE and family members appreciated the value of having access to an ESN, a minority of PWE continued to express reservations during the focus groups. It appeared, in the absence of information on the rationale for the development of the role, some PWE were concerned about ESN's level of knowledge, especially in relation to medication (E8), while others questioned whether the introduction of ESNs was a cost-saving initiative introduced in response to the current resource-stretched Irish health care environment (E9).

\section{DISCUSSION}

The findings of the study posit a number of factors influencing the implementation of the ESN role. These factors (positive and negative) are classified using the five domains of the Consolidation Framework for Implementation Research (CFIR) (Damschroder et al., 2009). 
While many implementation theories and frameworks exist (Berkel et al., 2011; Chaudoir et al. 2013; Damschroder et al., 2009; Durlak \& DuPre, 2008), with the exception of Elliott et al.'s (2016) review of issues influencing the leadership role of advanced practitioner's, this is the first study to our knowledge that used an implementation theory to identify factors influencing implementation of advanced practice roles. The limited use of implementation theories to guide studies may be related to the newness of implementation science within nursing or a belief that implementation theories have nothing to offer researchers in this area. Irrespective of reasons, their absence within the studies has resulted in a lack of cohesion and consistency in the manner evidence is produced, with many possible issues left unexplored.

Although little research exists on the factors that support the implementation of ESN roles, in other areas of nursing barriers and enablers to the development of advanced practice roles have been identified (Begley et al. 2010; Elliott et al. 2016; Higgins et al. 2014). The majority of this research tends to focus on the inner context of the organisation and the impact of interprofessional relationships. Concerns by medical colleagues around malpractice and potential legal liability have been reported in the international literature (DiCenso et al., 2010; Elliott et al., 2016; Gerrish et al., 2011; Hourahane et al., 2012; McIntosh and Tolsen, 2009). In contrast to international experiences, the leadership and mentorship provided by senior medical and nursing personnel in the study were key implementation enablers and in line with findings of another Irish study on advanced practice roles, although not ESNs (Begley et al., 2010). The support invested by nursing and medical personnel within the inner setting no doubt reflects the impact of outer level policies, such as the NCNM document (NCNM, 2008) and the NECP (HSE, 2014), which ensured funding, standard operating procedures and a strategic and more defined role for the ESN. While both documents acted as 
enablers to role implementation, the inadequate consideration of and planning for the management of clinical workload capacity and service development capacity within the NECP (HSE, 2014), the demands of the site preparation and accreditation process, together with the restrictions in relation to site and post approval as stipulated in the NCNM (2008) emerged as a potential barriers.

An additional issue that plagues health services internationally are concerns about nurses' having the competence to undertake roles that are considered the remit of other disciplines, such as medication prescribing (Delamaire and Lafortune, 2010; Keating et al., 2010; Lindblad et al., 2010; Pulcini et al., 2010; ). These worries did not emerge within this study, participants in all disciplines commented on the education, expertise and personal qualities of the ESN as a critical enabler of the role. This positive assessment of competence no doubt reflects the fact that the ESNs involved were very experienced and well educated clinicians. In particular, medical consultants were strong supporters of ESNs expanding their scope of practice, as evidenced by their supervision and mentoring. However, they did express concern about the challenge of mentoring ESNs while maintaining their own clinical workload. Furthermore, while previous research indicated that PWE who are cared for by an ESN, do not, at follow-up, have a preference for who provides their care (Mills et al, 1999, 2002), findings from our study indicated that some PWE prefer a medical consultant to provide their care as they trust their advice more, especially in relation to medication. While the majority of PWE and family members were supportive of the ESN role, this highlight the risk of assuming PWE and their family accept the role, and foregrounds the importance of services factor consultation with PWE into implementation plans. This is especially important 
in challenging economic climates, as development within services could be interpreted as cost-saving devices.

Although deficits in formal support mechanisms have emerged as barriers in previous research (Booth et al., 2006; Elliott et al., 2016), this was not an issue in this study. Data indicated that the ESNs had created a number of support structures that spanned discipline, organisation, and national borders. Where support arose as an issue, it was associate with the lone practitioner model and related to role isolation, an issue identified in a previous Irish study (Begley et al. 2010). Linked to role isolation was a concern around the impact of the lone practitioner model on the sustainability of services.

Similar to other studies that highlight how service demands and administrative activities take precedence over other dimensions of the role (Kilpatrick et al., 2012; Mullen and GavinDaley, 2010; Guest et al., 2004; Ridley et al, 2000), findings from this study also reveal how ESNs can become victims of their own success. In the absence of clear national parameters around case load and service development capacity, ESNs were reaching a stage where demand was outstripping resources. Consequently, there were concerns and questions about the ability of ESNs continuing service developments at the same pace, without impacting the quality of service and risking burnout. In addition, the demands of developing services, managing large clinical caseloads, and achieving the requirements to register as an ANP, coupled with the stress and responsibility of the role were viewed as barriers to other nurses pursuing an ANP pathway, which has the potential to impact the sustainability of the roles in the long term. 
Other factors influencing implementation of the role were related to infrastructural supports. The level of personnel and IT resources varied across services, with some having poor access to such support, providing care inadequate physical environments and, in some cases, lacking access to online library resources. In other Irish (Begley et al., 2010; Higgins et al., 2014; NCNM, 2005) and international (Donald et al., 2011; Gerrish et al., 2011) studies comparable deficiencies in infrastructural supports, available to advanced practice roles have been highlighted. As well as structural and IT resources, carving out time was a barrier to the ESNs conducting research, having time to create a vision for the service and take a long-term perspective. All critical issues if ongoing service development is to be strategically planned and grounded with an evidence base.

Whilst the study provides useful evidence on the facilitators and enablers to the implementation of the ESN role and the CIFR offers a useful typology there are certain limitations that need to be borne in mind. The CIFR was used as a structure to support the analysis post data collection, had it guided both the data collection and analysis, other factors within each of the domains may have been identified. Second, it is not possible to generalise the findings beyond the five centres involved. While data were triangulated and analysis performed by three researchers, there is always the potential for bias, including social desirability bias, analytical bias and observer bias during the observation.

\section{RELEVANCE FOR CLINICAL PRACTICE}

The factors influencing implementation of the ESN role within complex and layered health services were identified within all five domains of the CFIR. While support for the ESN role was overwhelmingly positive among all participants, the findings highlight a need to address 
the ESN workload capacity, the effect of the lone practitioner model on services, the impact of service expansion on the quality of service provided, as well as the impact on the mentoring and supervision workload of medical consultants, should the numbers of ESNs expand. In addition, there is a need for ESNs and other stakeholders to engage with PWE and family members around the role and to address the deficits in structural supports to enable ESNs to meet the research dimensions of the role as well as find time to plan strategically. Findings also suggest that the CFIR offers a pragmatic typology for analysing evidence in this area, while also offering future researchers a theoretical basis to assist them explore the interrelationship between the five domains.

\section{REFERENCES}

Begley, C., Murphy, K., Higgins, A, Elliott, N., Lalor, J., Sheerin, F., Coyne, I., Comiskey, C., Normand, C., Casey, C., Dowling, M., Devane, D., Cooney, A., Farrelly, F., Brennan, M., Meskell, P., \& MacNeela, P. (2010). Evaluation of Clinical Nurse and Midwife Specialist and Advanced Nurse and Midwife Practitioner Roles in Ireland (SCAPE): Final Report. Dublin, Ireland: National Council for the Professional Development of Nursing and Midwifery in Ireland. Retrieved from http://www.tara.tcd.ie/handle/2262/68341 (090719)

Berkel, C., Mauricio, A., Schoenfelder, E., \& Sandler, I. (2011). Putting the Pieces Together: An Integrated Model of Program Implementation. Prevention science: the official journal of the Society for Prevention Research, 12, 23-33. 10.1007/s11121-010-01861.

Booth, J., Hutchison, C., Beech, C., \& Robertson, K. (2006). New nursing roles: the experience of Scotland's consultant nurse/midwives. Journal of Nursing Management, 14(2), 83-89. https://doi.org/10.1111/j.1365-2934.2006.00595.x

Bradley, P. M., Lindsay, B., \& Fleeman, N. (2016). Care delivery and self management strategies for adults with epilepsy. Cochrane Database Systematic Reviews, 2, CD006244. 
Casey, M., O’Connor, L., Cashin, A., Fealy, G., Smith, R., O’Brien, D., Stokes, D., McNamara, M., O’Leary, D., Glasgow, M.E (2019) Enablers and challenges to advanced nursing and midwifery practice roles Journal of Nursing Management 27(2),271-277.

Chaudoir, S. R., Dugan, A. G., \& Barr, C. H. (2013). Measuring factors affecting implementation of health innovations: a systematic review of structural, organizational, provider, patient, and innovation level measures. Implementation science, 8, 22. doi:10.1186/1748-5908-8-22

Damschroder, L., Aron, D., Keith, R., Kirsh, S., Alexander, J., \& Lowery, J. (2009). Fostering implementation of health services research findings into practice: A consolidated framework for advancing implementation science. Implementation science, 4, 50. https://doi.org/10.1186/1748-5908-4-50

Delamaire, M., \& Lafortune, G. (2010). Nurses in Advanced Roles: A Description and Evaluation of Experiences in 12 Developed Countries. OECD Health Working Papers, No. 54. Paris, France: OECD Publishing. Retrieved from https://www.oecdilibrary.org/social-issues-migration-health/nurses-in-advanced-roles $5 \mathrm{kmbrcfms} 5 \mathrm{~g} 7$ $\underline{\text { en }}$

DiCenso, A., Martin-Misener, R., Bryant-Lukosius, D., Bourgeault, I., Kilpatrick, K., Donald, F., Kaasalainen, S., Harbman, P., Carter, N., Kioke, S., Abelson, J., McKinlay, R.J., Pasic, D., Wasyluk, B., Vohra, J., \& Charbonneau-Smith, R. (2010). Advanced practice nursing in Canada: overview of a decision support synthesis. Nursing Leadership (Toronto Ont), 2, 15-34.

Donald, F., Martin Misener, R., Bryant-Lukosius, D., DiCenso, A., Ploeg, J., Brazil, K., Kaasalainen, S., Schindel Martin, L., Stolee, P., McAiney, C., Carter, N., Dobbins, M., Taniguchi, A., \& Akhtar-Danesh, N. (2011). Understanding the Individual, Organizational, and System Factors Influencing the Integration of the Nurse Practitioner Role in Long-Term Care Settings in Canada. Retrieved from http://www.ryerson.ca/apnltc/pdf/FinalReport.pdf (09.07.19)

Durlak, J. A., \& P DuPre, E. P. (2008). Implementation Matters: A Review of Research on the Influence of Implementation on Program Outcomes and the Factors Affecting Implementation. American journal of community psychology, 41, 327-50. 10.1007/s10464-008-9165-0. 
Elliott, N., Begley, C., Sheaf, G., \& Higgins, A. (2016). Barriers and enablers to advanced practitioners' ability to enact their leadership role: A scoping review. International Journal of Nursing Studies, 60, 24-45. doi: 10.1016/j.ijnurstu.2016.03.001

Gerrish, K., Guillaume, L., Kirshbaum, M., McDonnell, A., Tod, A., \& Nolan, M. (2011). Factors influencing the contribution of advanced practice nurses to promoting evidence-based practice among front-line nurses: findings from a cross-sectional survey. Journal of Advanced Nursing, 67(5), 1079-1090. doi: 10.1111/j.13652648.2010.05560.x.

Goodwin, M., Higgins, S., Lanfear, J. H., Lewis, S., \& Winterbottom, J. (2004). The role of the clinical nurse specialist in epilepsy. A national survey. Seizure, 13(2), 87-94.

Guest, D., Peccei, R., Rosenthal, P., Redfern, S., Wilson-Barnett, J., Dewe, P., Coster, S., Evans, A., \& Sudbury, A. (2004) An Evaluation of the Impact of Nurse, Midwife and Health Visitor Consultants. London: King's College London.

Health Service Executive (HSE). (2014). The National Clinical Programme in Epilepsy Care in Ireland. Dublin, Irleand: HSE.

Higgins, A., Begley, C., Lalor, J., Coyne, I., Murphy, K., \& Elliott, N. (2014). Factors influencing advanced practitioners' ability to enact leadership: a case study within Irish healthcare. Journal of Nursing Management, 22(7), 894-905. doi: 10.1111/jonm.12057.

Higgins, A., Downes, C., Varley, J., Tyrell, E., Normand, C., Doherty, C. P., Begley, C., \& Elliott N. (2018a). Rising to the challenge: Epilepsy specialist nurses as leaders of service improvements and change (SENsE study). Seizure: European Journal of Epilepsy, 63, 40-47. DOI: 10.1016/j.seizure.2018.10.013.

Higgins, A., Downes, C., Varley, J., Tyrell, E., Normand, C., Doherty, C. P., Begley, C., \& Elliott N. (2018b). Patients with epilepsy care experiences: Comparison between services with and without an epilepsy specialist nurse. Epilepsy Behavior, 85, 85-94. doi: 10.1016/j.yebeh.2018.05.038.

Higgins, A., Downes, C., Varley, J., Tyrell, E., Normand, C., Doherty, C. P., Begley, C., \& Elliott N. (2019a). Evidence-based practice among Epilepsy Specialist Nurses in Ireland: findings from the SENsE study. Journal of Nursing Management, 27, 4, 840847. DOI: $10.1111 /$ jonm.12747. 
Higgins, A., Downes, C., Begley, C., Varley, J, Doherty, C.P., \& Elliott, N. (2019b).

Supporting and empowering people with epilepsy: Contribution of the Epilepsy Specialist Nurses (SENsE study). Seizure: European Journal of Epilepsy, 71, 42-49. https://doi.org/10.1016/j.seizure.2019.06.008

Hopkins, J., Irvine, F., Krska, J., Curran, A., Stokes, L., Halsall, S., James, M., \& Morecroft, C. (2010). Identifying and monitoring the cost-effectiveness of the Epilepsy Specialist Nurse. Leeds: Epilepsy Action.

Hopkins, J., \& Irvine, F. (2012). Qualitative insights into the role and practice of epilepsy specialist nurses in England: A focus group study. Journal of Advanced Nursing, 68(11), 2443-2453. DOI: 10.1111/j.1365-2648.2012.05941.x.

Hourahane, G., West, N., Barnes, R., Rees, S., Bowyer, A., Dundon, J., \& Allen, D. (2012). Supporting trail-blazing: A systematic review of the factors that facilitate or inhibit the implementation of new nursing roles: the experiences of UK consultant nurses. JBI Library of Systematic Reviews, 10(50), 3146 - 3294. DOI:10.11124/jbisrir-201221

Keating, S. F. J., Thompson, J. P., \& Lee, G. A. (2010). Perceived barriers to the sustainability and progression of nurse practitioners. International Emergency Nursing, 18(3), 147-153. DOI: 10.1016/j.ienj.2009.09.003

Kengne, A. P., Fezeu, L. L., Awah, P. K., Sobngwi, E., Dongmo, S., \& Mbanya, J. C. (2008). Nurse-led care for epilepsy at primary level in a rural health district in Cameroon. Epilepsia, 49(9), 1639-1642.doi:10.1111/j.1528-1167.2008.01580_2.x

Kilpatrick, K., Lavoie-Tremblay, M., Ritchie, J. A., Lamothe, L., Doran, D., \& Rochefort, C. (2012). How are acute care nurse practitioners enacting their roles in healthcare teams? A descriptive multiple-case study. International Journal of Nursing Studies, 49(7), 850-862. DOI:10.1016/j.ijnurstu.2012.01.011

Kilpatrick, K., Lavoie-Tremblay, M., Lamothe, L., Ritchie, J. A., \& Doran, D. (2013). Conceptual framework of acute care nurse practitioner role enactment, boundary work, and perceptions of team effectiveness. Journal of Advanced Nursing, 69(1), 205-217. DOI: 10.1111/j.1365-2648.2012.06046.x

Lindblad, E., Hallman, E.-B., Gillsjö, C., Lindblad, U., \& Fagerström, L. (2010). Experiences of the new role of advanced practice nurses in Swedish primary health care-A 
qualitative study. International Journal of Nursing Practice, 16(1), 69-74. DOI: 10.1111/j.1440-172X.2009.01810.x.

Lowe, G., Plummer, V., O'Brien, A. P., \& Boyd, L. (2012). Time to clarify the value of advanced practice nursing roles in health care. Journal of Advanced Nursing, 68(3), 677-685. DOI:10.1111/j.1365-2648.2011.05790.x

McIntosh, J., \& Tolson, D. (2009). Leadership as part of the nurse consultant role: banging the drum for patient care. Journal of Clinical Nursing, 18(2), 219-227. DOI: 10.1111/j.1365-2702.2008.02520.x

Mills, N., Bachmann, M. O., Harvey, I., Hine, I., \& McGowan, M. (1999). Effect of a primary-care-based epilepsy specialist nurse service on quality of care from the patients' perspective: Quasi-experimental evaluation. Seizure, 8(1), 1-7.

Mills, N., Campbell, R., \& Bachmann, M. O. (2002). What do patients want and get from a primary care epilepsy specialist nurse service? Seizure, 11(3), 176-183. DOI: 10.1053/seiz.2001.0615

Mullen, C. and Gavin-Daley, A. (2010). Ten Years on-An Evaluation of the Non-Medical Consultant Role in the North West. NHS North West, UK: NHS North West.

National Institute for Health and Clinical Excellence (NICE) (2012). Epilepsies: diagnosis and management. Clinical guideline. London: NICE.

National Council for the Professional Development of Nursing and Midwifery (NCNM) (2005). A Preliminary Evaluation of the Role of the Advanced Nurse Practitioner. Dublin, Ireland: NCNM.

National Council for the Professional Development of Nursing and Midwifery (2008). Framework for the Establishment of Advanced Nurse Practitioner and Advanced Midwife Practitioner Posts. Dublin, Ireland: NCNM.

Noble, A. J., Morgan, M., Virdi, C., \& Ridsdale, L. (2013). A nurse-led self-management intervention for people who attend emergency departments with epilepsy: the patients' view. Journal of Neurology, 260(4), 1022-1030. doi:10.1007/s00415-012-6749-2

Pfäfflin, M., Schmitz, B., \& May, T. W. (2016). Efficacy of the epilepsy nurse: Results of a randomized controlled study. Epilepsia, 57(7), 1190-1198. DOI:10.1111/epi.13424

Plager, K.A., \& Conger, M. M. (2007). Advanced practice nursing: Constraints to role fulfillment. International Journal of Advanced Nursing Practice, 9(1), 1523-6064. 
Pulcini, J., Jelic, M., Gul, R., \& Loke, A. Y. (2010). An International Survey on Advanced Practice Nursing Education, Practice, and Regulation. Journal of Nursing Scholarship, 42(1), 31-39. DOI: 10.1111/j.1547-5069.2009.01322.x

Ridley, J., Harwood, L., Lawrence-Murphy, J. A., Locking-Cusolito, H., \& Wilson, B. (2000). How five advanced practice nurses in nephrology spend their time. CANNT Journal, 10(4), 38-42.

Table 1 Data collection method and sources

\begin{tabular}{|l|l|}
\hline Data collection method & Data source \\
\hline Individual interview & Epilepsy Specialist Nurses \\
$\begin{array}{l}\text { Document (portfolios, documents recording curriculum } \\
\text { activity, education input, guideline developed, } \\
\text { research/audit) }\end{array}$ & Directors of Nursing/ Assistant Directors =5 \\
\hline $\begin{array}{l}\text { Individual interviews } \\
\text { Focus groups x 5 }\end{array}$ & Clinical Nurse Managers $=2$ \\
\hline
\end{tabular}

Table 2: Interview and observation schedules 
Interview schedule (ESN and MDT)

- Background to role and development of role

- In the development of role where there things that helped (patient, provider, health system and health policy)

- In the development of role what, if any barriers, were encountered (patient, provider, health system and health policy)?

- What do you think helped in overcoming the barriers?

- How would you like to see the service expanded/changed/modified in the future

- What advice would you give people considering developing an ENS service.

Observation schedule (ESN)

- Services delivered

- Context of care (physical environment, MDT members, governance structures)

- Evidence of support from MDT (mentorship, supervision, educational supports)

- Interaction with patient and family (attitudes, level of acceptance)

Focus group schedule (PWE and Family)

- Relationship with the ESN

- Satisfaction with Role

- Barrier to using ESN service

- Concerns, if any, about the ESN service

Table 3 Overview of the Consolidation Framework for Implementation Research

\begin{tabular}{|l|l|}
\hline Domain & Meaning \\
\hline Outer setting & $\begin{array}{l}\text { The wider social/political/economic context which the organisation is } \\
\text { embedded within. The focus of this domain is on exploring impact of } \\
\text { international and national policies, as well as the extent to which patient } \\
\text { needs are known, prioritised and addressed through provision of resources } \\
\text { and incentives. This domain also looks at the level of competitive pressure } \\
\text { from outside organisation and peers to implement change. }\end{array}$ \\
\hline Inner setting & $\begin{array}{l}\text { The structural and cultural characteristics of the organisation/service where } \\
\text { the intervention is implemented. The focus of this domain is on constructs } \\
\text { such as culture, leadership, mentoring, networking, communication patterns } \\
\text { and implementation climate (degree people see need for change, provision } \\
\text { of infrastructural supports, incentives, ease of access to informational and } \\
\text { knowledge sources). }\end{array}$ \\
\hline Intervention & $\begin{array}{l}\text { Intervention refer to the characteristics of the intervention, and focuses on } \\
\text { source of intervention (internal or external), strength of evidence to support } \\
\text { its use, the level of complexity or adaptability in relation to } \\
\text { implementation, advantage of using one intervention over another, as well } \\
\text { as design quality and costs associated with implementation. }\end{array}$ \\
\hline Individual & \begin{tabular}{l} 
Addresses the individual provider(s) of the intervention. The focus of this \\
\hline
\end{tabular}
\end{tabular}




\begin{tabular}{|l|l|}
\hline & $\begin{array}{l}\text { domain is on the person's knowledge and beliefs about the intervention, } \\
\text { their self-efficacy in relation to providing the intervention, and other } \\
\text { personal attributes that may impact implementation, such as motivation, } \\
\text { nature of work contract, past experiences. }\end{array}$ \\
\hline $\begin{array}{l}\text { Implementation } \\
\text { process }\end{array}$ & $\begin{array}{l}\text { The implementation domain addresses the activities undertaken as part of } \\
\text { the implementation process. The focus of this domain is on constructs such } \\
\text { as planning, engagement of appropriate individuals, quality of the } \\
\text { execution process and evaluation methods. }\end{array}$ \\
\hline
\end{tabular}

Table 4: Demographic profile of ESNs

\begin{tabular}{|c|c|}
\hline Employment status & $\begin{array}{l}\text { Full-time }=10 \\
\text { Part-time }=2\end{array}$ \\
\hline Time in current post & Mean $=5.42$ years; Range $=2-21$ years \\
\hline $\begin{array}{l}\text { Length of time since } \\
\text { registration as a nurse }\end{array}$ & Mean 20.92 years; Range $=12-34$ years \\
\hline $\begin{array}{l}\text { Professional } \\
\text { qualifications }\end{array}$ & $\begin{array}{l}\text { Registered General Nurse }(\mathrm{n}=12) \\
\text { Registered Children's Nurse }(\mathrm{n}=4) \\
\text { Registered Nurse in Intellectual Disability }(\mathrm{n}=2) \\
\text { Registered Midwife }(\mathrm{n}=1) \\
\text { Registered Prescriber of Medicinal Products }(\mathrm{n}=7) \\
\text { Registered Prescriber of Ionizing Radiation }(\mathrm{n}=1) \\
\text { Registered Advanced Nurse Practitioners }(\mathrm{n}=2)\end{array}$ \\
\hline $\begin{array}{l}\text { Epilepsy-specific } \\
\text { qualifications }\end{array}$ & $\begin{array}{l}\text { MSc Epilepsy/advanced practice (epilepsy) } n=5 \\
\text { Diploma/Postgraduate Diploma in epilepsy care/advanced practice } \\
\text { epilepsy care } n=6 \\
\text { Certificate in Epilepsy } n=2 \\
\text { Currently completing MSc in Epilepsy/Advanced Practice (Epilepsy ) } n=3\end{array}$ \\
\hline
\end{tabular}




\begin{tabular}{|l|l|}
\hline Other qualifications & Masters in Nursing \\
BSc in Nursing Studies \\
Post graduate/higher diploma/diploma in: Neuroscience Nursing; Critical \\
Care; Women's Health; Management; Intensive Care \\
BSc in Nursing Management \\
Certificate in: Intensive Care; Anaesthetic room recovery; Infection \\
Control
\end{tabular}

Table 5 Data to support domains

\begin{tabular}{|c|c|}
\hline \multicolumn{2}{|c|}{ Domain A: Outer Setting } \\
\hline A1 & $\begin{array}{l}\text { We met [National Clinical Lead in Epilepsy], they want ANPs in epilepsy } \\
\text { across the country... having somebody who is immersed in epilepsy it is going } \\
\text { to have improved outcomes... ...we got funding [for nurses] and it is the best } \\
\text { model of care for patients with epilepsy (DoN interview) }\end{array}$ \\
\hline A2 & $\begin{array}{l}\text { We [ESNs] were part of the National Care Programme so there was all the } \\
\text { SOPs [Standard Operating Procedures] and KPIs [Key Performance } \\
\text { Indicators], which were great guidelines for us at the start. (RANP interview) }\end{array}$ \\
\hline A3 & $\begin{array}{l}\text { I've got funding as part of the National Care Programme, it's facilitating my } \\
\text { education for my role. (ANPc interview) }\end{array}$ \\
\hline A4 & $\begin{array}{l}\text { The good thing about the site preparation, it does give you clarity, it gives your } \\
\text { role clarity and it does bring buy-in and it is a blueprint for the future.(ANPc } \\
\text { interview) }\end{array}$ \\
\hline A5 & $\begin{array}{l}\text { They (ANP posts) are not always transferrable if you do want to move outside } \\
\text { of a hospital or organisation... you start [the approval process] from scratch, } \\
\text { start again with your accreditation. (MDT interview) }\end{array}$ \\
\hline A6 & $\begin{array}{l}\text { I think some people [nurses] think it's a lot of unnecessary stress...some of my } \\
\text { colleagues can see what I've had to go through [preparing for ANP role]...one } \\
\text { obstacle after another...they wonder like why go through that. (RANP } \\
\text { interview) }\end{array}$ \\
\hline A7 & $\begin{array}{l}\text { The NMBI, came out and did a meeting in the hospital and I found that very } \\
\text { beneficial because it sort of puts you on the right road [on accreditation } \\
\text { process] instead of going off the wrong track. (ANPc interview) }\end{array}$ \\
\hline A8 & $\begin{array}{l}\text { We have an [national] email forum... I can email [name of ESN and RANP] } \\
\text { who is the head of the forum and she will pass on my query to everybody else. }\end{array}$ \\
\hline
\end{tabular}




\begin{tabular}{|c|c|}
\hline & $\begin{array}{l}\text {...you get emails if something comes out, if there's kind of new trends in } \\
\text { something. (ANPc interview) }\end{array}$ \\
\hline A9 & $\begin{array}{l}\text { I'm very involved with the Irish Epilepsy Nurses' Group... the main aim is to } \\
\text { support nurses who work with patients with epilepsy, in whatever sector that is, } \\
\text { be it intellectual disability, paediatrics, psychiatric...we have educational } \\
\text { meetings and we have a national conference once a year and go to } \\
\text { international conferences. (RANP interview) }\end{array}$ \\
\hline A10 & $\begin{array}{l}\text { Candidate ANP went to [name of hospital] to work and shadow RANP before } \\
\text { setting up own Vagal Nerve Stimulation clinic. RANP from [name of hospital] } \\
\text { also visited to follow-up with [candidate ANP] and ensure competence. (ANPc } \\
\text { observation) }\end{array}$ \\
\hline A11 & $\begin{array}{l}\text { Evidence of acting as a consultant to epilepsy services outside of [own } \\
\text { organisation] to assist and advise in setting up nurse-led outreach clinics. } \\
\text { (RANP documentary evidence) }\end{array}$ \\
\hline A12 & $\begin{array}{l}\text { We've had to bring the [RANPs] from [names hospital] down over the } \\
\text { Electronic Patient Record... we've received a lot of support. (ANPc interview) }\end{array}$ \\
\hline \multicolumn{2}{|c|}{ Domain B: Inner setting } \\
\hline B1 & $\begin{array}{l}\text { We have a supportive neurologist [name of consultant], we have a supportive } \\
\text { neurology team of consultants, who very much value the role. (DoN interview) }\end{array}$ \\
\hline B2 & $\begin{array}{l}\text { It's a local thing, any of them [allied health professionals], at the moment don't } \\
\text { accept referrals from anybody only medicine but I believe they're addressing } \\
\text { it...(ANPc interview) }\end{array}$ \\
\hline B3 & $\begin{array}{l}\text { I think the biggest... it would be our nurse divisional manager, which is our } \\
\text { ADoN...she would have been the biggest driver. (ANPc interview) }\end{array}$ \\
\hline B4 & $\begin{array}{l}\text { Our nurse administration was on-board from day one. It was welcomed and it } \\
\text { was embraced. (Allied health professional interview) }\end{array}$ \\
\hline B5 & $\begin{array}{l}\text { [Name of consultant] is concurrently running a neurology clinic in OPD and is } \\
\text { available to the ESN, if required. He is the clinical mentor for this ESN (ANPC } \\
\text { observation) }\end{array}$ \\
\hline B6 & $\begin{array}{l}\text { [Name of consultant] gave the nurses a huge amount of freedom ... which } \\
\text { allowed [them] to make decisions and grow things....(Allied health professional } \\
\text { interview) }\end{array}$ \\
\hline B7 & $\begin{array}{l}\text { [Epilepsy consultants], they're very approachable. If you have any issues with } \\
\text { patients it's no problem, emailing them, ringing them... we can ask them } \\
\text { questions about a patient that you're worried about but you've the facility to say } \\
\text { I don't understand, can you explain this to me (ANPc interview) }\end{array}$ \\
\hline $\mathrm{B} 8$ & $\begin{array}{l}\text { It's great to say that an experienced nurse practitioner can see new patients in } \\
\text { a clinical environment, but they need to be trained up on the physical and } \\
\text { neurological exam, which we are doing, but it takes time. (Medical personnel } \\
\text { interview) }\end{array}$ \\
\hline B9 & The Director of Nursing has been very supportive in terms of study days... when \\
\hline
\end{tabular}




\begin{tabular}{|c|c|}
\hline & $\begin{array}{l}\text { I did my Advanced Practice module, I had my time off, the same with nurse } \\
\text { prescribing. (RANP interview) }\end{array}$ \\
\hline B10 & $\begin{array}{l}\text { We have great support, even for developing the role as an ANP. There's a group } \\
\text { (RANP group) here within the hospital and the ANPs are very supportive so } \\
\text { we've plenty of places we can go to ask for help." (ANPc interview) }\end{array}$ \\
\hline B11 & $\begin{array}{l}\text { Candidate ANP seeks advice from RANP on patient case involving substance } \\
\text { misuse and epilepsy. RANP advises [candidate ANP] to link in with the } \\
\text { psychology team who is currently working with this patient, to ring local } \\
\text { pharmacy to check prescription, to contact [name drug addiction service] to } \\
\text { discuss the issue of drugs in urine and get their perspective, also advises } \\
\text { candidate ANP not to change medications until a full review with MDT team } \\
\text { including psychology and psychiatry. (ANPc observation) }\end{array}$ \\
\hline B12 & $\begin{array}{l}\text { He (consultant epileptoligist) is our medical mentor, He's very proactive in } \\
\text { audit and he encourages us strongly to get involved in audit, we've done three } \\
\text { and we have a fourth now in progress but we haven't done research in this job, } \\
\text { except for my Masters (ANPC interview). }\end{array}$ \\
\hline B13 & $\begin{array}{l}\text { We have a big research project that they (ESNs) are involved in, we are } \\
\text { actually analysing all the results, we have another research proposal which has } \\
\text { gone to Ethics Committee, they are helping with that -. But specifically their } \\
\text { own thing is audit (Medical personnel interview) }\end{array}$ \\
\hline B14 & $\begin{array}{l}\text { If research is the discovery of new things, we haven't done a lot of that... When } \\
\text { there is a busy clinical service, it [doing research] is difficult...this would be a } \\
\text { potential criticism say of my own service... it is hard for the ESNs to develop a } \\
\text { significant research component to their work, when we're [medical team] not } \\
\text { doing it either. (Medical personnel interview) }\end{array}$ \\
\hline B15 & $\begin{array}{l}\text { I organise, I do all my own administrative work, so I send out appointment } \\
\text { letters and everything, I do the whole lot, so I don't get really any support, I do } \\
\text { everything you know. I do the whole lot. (ANPc interview) }\end{array}$ \\
\hline B16 & $\begin{array}{l}\text { ESN uses lunch break to deliver referral form to a central administration } \\
\text { location in hospital. She also delivers other referral sheets into a post box } \\
\text { along the way. ESN does not have administrative support. (ANPc observation) }\end{array}$ \\
\hline B17 & $\begin{array}{l}\text { So every patient, we have to go through the whole chart and put this patient } \\
\text { onto the EPR, it's very time consuming, you might have a patient who has a } \\
\text { history, thirty year history of epilepsy, and you're going through what } \\
\text { medications they were on before, why they were stopped, when they were } \\
\text { stopped, what dose they got to. So you're literally, that could take an hour to go } \\
\text { through that chart, it could take more for some. (ANPc interview) }\end{array}$ \\
\hline B18 & $\begin{array}{l}\text { The room is small, narrow, not a clinical room and does not have obvious } \\
\text { resuscitation equipment which is necessary given the type and complexity of } \\
\text { patient being reviewed. [ESN] states 'we have big problems with space' and } \\
\text { 'sometimes rooms are not the best. (ANPc observation) }\end{array}$ \\
\hline B19 & $\begin{array}{l}\text { Met ESN in office that is shared by } 3-4 \text { other nurse specialists. (RANP } \\
\text { observation) }\end{array}$ \\
\hline
\end{tabular}




\begin{tabular}{|c|c|}
\hline B20 & $\begin{array}{l}\text { Most of the hiccups have not been clinical. They have been in terms of the } \\
\text { actual running of the clinic and information technology and support that has } \\
\text { been extremely challenging. (Allied health professional interview) }\end{array}$ \\
\hline B21 & $\begin{array}{l}\text { [ESN] notes that the EPR is a great system for keeping track of MDT } \\
\text { communication and interventions etc., but that it does take time to complete and } \\
\text { you can't complete a draft and save, so you must complete immediately and } \\
\text { within a } 20 \text { minute timeframe, so need to be very organised and not get } \\
\text { distracted by other things, as could lose the data entered. (RANP observation) }\end{array}$ \\
\hline B22 & $\begin{array}{l}\text { I have access to the [names university] library until October and I'm dreading } \\
\text { it then, I don't know what I'll do, I'm going to lose my access in October } \\
\text { [finishing her educational programme] so, it's going to be a huge loss to me. } \\
\text { (ANPc interview) }\end{array}$ \\
\hline \multicolumn{2}{|c|}{ Domain C: Characteristics of the intervention } \\
\hline $\mathrm{C} 1$ & $\begin{array}{l}\text { I find [name of ESN] brilliant. I was pregnant at the time and you don't want } \\
\text { anything to happen. Anytime I ring her up she's straight back on... if she's busy } \\
\text { or whatever, she'll ring me within the hour and she'd always sort me out. } \\
(P W E)\end{array}$ \\
\hline $\mathrm{C} 2$ & $\begin{array}{l}\text { The one on one [relationship] and the continuity between a nurse and yourself, } \\
\text { they get to know you. }(P W E)\end{array}$ \\
\hline C3 & $\begin{array}{l}\text { The nurses [ESN's] who look after you before and after [surgery], you couldn't } \\
\text { get better. They're like another family, they're always there. (PWE) }\end{array}$ \\
\hline $\mathrm{C} 4$ & $\begin{array}{l}\text { [name of ESN] is always there, which does make a difference... Sometimes you } \\
\text { can feel very isolated and it's a frightening place to be when you don't have } \\
\text { anyone who understands. }(P W E)\end{array}$ \\
\hline $\mathrm{C} 5$ & $\begin{array}{l}\text { She's [ESN] amazing... each time we go [to the clinic], we don't have to repeat } \\
\text { the whole lot [history]. [Name of ESN] always, always knows. (Family } \\
\text { member) }\end{array}$ \\
\hline C6 & $\begin{array}{l}\text { Their knowledge comes across so strongly that it gives you confidence in them. } \\
\text { (Family member) }\end{array}$ \\
\hline C7 & $\begin{array}{l}\text { There's one person who provides a very, very specialised service and is highly } \\
\text { skilled within that service. If that person is on leave, for whatever reason, that } \\
\text { can be a huge shortfall for the service...I'm not sure that is a great way to run } \\
\text { a service...it results in an enormous gap in the service... (DoN interview) }\end{array}$ \\
\hline $\mathrm{C} 8$ & $\begin{array}{l}\text { We learned an expensive lesson when our nurse practitioner went on leave. } \\
\text { There was no backfill, you could see the impact. Even the number of medical } \\
\text { consultations increased, the epilepsy attendances in ED increased, we had to } \\
\text { discontinue clinics. (Medical personnel interview) }\end{array}$ \\
\hline C9 & $\begin{array}{l}\text { It has been a very isolating journey, you know, from the start... you're trying to } \\
\text { evolve a service, evolve your role and there's so much for you to do within that } \\
\text { pathway ...I would be envious of other centres that would have [more than one] } \\
\text { ANP because they can bounce ideas off each other. (ANPc interview) }\end{array}$ \\
\hline $\mathrm{C} 10$ & $\begin{array}{l}\text { ESN is trying to arrange admission for the patient. The bed manager informs } \\
\text { ESN by telephone that no bed is available. ESN speaks with the psychiatry team } \\
\text { on call and with the neurology medical register. There is a protracted }\end{array}$ \\
\hline
\end{tabular}




\begin{tabular}{|c|c|}
\hline & $\begin{array}{l}\text { discussion on which team should admit the patient and where to keep the } \\
\text { patient until a bed for admission becomes available. The neurology registrar on } \\
\text { call suggests that the patient should be transferred to the ED until a bed } \\
\text { becomes available. ESN challenges respectfully this suggestion and feels this is } \\
\text { an inappropriate solution (i.e. "ED is not a suitable place for this patient"). } \\
\text { However from their discussion it appears there is no alternative to this solution. } \\
\text { The patient is transferred to the ED. (RANP observation) }\end{array}$ \\
\hline $\mathrm{C} 11$ & $\begin{array}{l}\text { I would like to (be doing research)... but the time constraints at the moment, } \\
\text { you know, it's very difficult for one person to run all these services and } \\
\text { incorporate everything (ANPc interview). }\end{array}$ \\
\hline $\mathrm{C} 12$ & $\begin{array}{l}\text { My protected time for research is zero, it's zero to be honest, it's just a time } \\
\text { thing, a time thing that I don't have. (RANP Interview) }\end{array}$ \\
\hline $\mathrm{C} 13$ & $\begin{array}{l}\text { The concern I would have is that they've taken on far too much clinically...they } \\
\text { don't have time to do the other parts of their roles, whether it be doing the } \\
\text { research side ...they're so totally focused on the patient, and that's very } \\
\text { important, but to fulfil their other roles and responsibilities, whether it be } \\
\text { leadership, audit and the research agenda. (DoN interview) }\end{array}$ \\
\hline $\mathrm{C} 14$ & $\begin{array}{l}\text { A huge time, chunk of my time in the last year has been taken up with site } \\
\text { preparation..., I don't think anything prepared you for it, just the time } \\
\text { consuming nature of it, that it takes you away from your patient clinical } \\
\text { outcomes, it's a lot of paperwork... it's a massive undertaking, from an } \\
\text { academic, clinical, trying to adjust to a new role, trying to...develop a new role } \\
\text { and then the site preparation. (ANPc interview) }\end{array}$ \\
\hline $\mathrm{C} 15$ & $\begin{array}{l}\text { I feel that the site preparation, has consumed everything, and at the moment } \\
\text { there is no time for me to do research (ANPc interview) }\end{array}$ \\
\hline $\mathrm{C} 16$ & $\begin{array}{l}\text { The greatest obstacle is being employed by [name Hospital] ... managed nursing } \\
\text { management at that service... but yet the [epilepsy] service is here [she delivers } \\
\text { an epilepsy service in another hospital]... both hospitals run very differently, so } \\
\text { this is a challenge (RANP interview) }\end{array}$ \\
\hline \multicolumn{2}{|c|}{ Domain D: Characteristics of individuals involved } \\
\hline D1 & $\begin{array}{l}\text { The ESN's level of knowledge and expertise in terms of epilepsy is far superior } \\
\text { than a regular staff nurse... they work at a very, very high level and they are } \\
\text { considered clinically expert at what they do. (DoN interview) }\end{array}$ \\
\hline D2 & $\begin{array}{l}\text { [Name of ESN]'s perseverance, her approach and her manner is critical. She's } \\
\text { very confident in what she does, but she's also extremely respectful (Allied } \\
\text { health professional interview) }\end{array}$ \\
\hline D3 & $\begin{array}{l}\text { The ESNs know when to escalate, but also are not the opposite of that, lacking } \\
\text { confidence and escalating everything. (Medical personnel interview) }\end{array}$ \\
\hline D4 & $\begin{array}{l}\text { They [ESNs] are a huge knowledge reservoir, and a huge support to people } \\
\text { with epilepsy and their families. (Medical personnel interview) }\end{array}$ \\
\hline D5 & She [ESN] is very confident giving direction, giving advice regarding certain \\
\hline
\end{tabular}




\begin{tabular}{|c|c|}
\hline & drugs, or lifestyle. (CNM interview) \\
\hline D6 & $\begin{array}{l}\text { Their keenness to learn is very significant... if people are willing to learn, they } \\
\text { provide a better service in general. (Medical personnel interview) }\end{array}$ \\
\hline D7 & $\begin{array}{l}\text { The people in the roles are very clearly innovators and want to continuously } \\
\text { improve things. (Allied health professional interview) }\end{array}$ \\
\hline D8 & $\begin{array}{l}\text { [ESNs] were very heavily involved in coming up with new ideas "let's do this", } \\
\text { "let's try that"....so they were very much innovators. (Medical personnel } \\
\text { interview) }\end{array}$ \\
\hline D9 & $\begin{array}{l}\text { I think it's their personality...they are very professional...spending time with } \\
\text { patients, and being interested in them is just another facet of that. (Medical } \\
\text { personnel interview) }\end{array}$ \\
\hline D10 & $\begin{array}{l}\text { I think they're never off duty ...no matter when you meet them. But I think } \\
\text { ultimately they're human...they don't see it as a job... it's a vocation. (PWE) }\end{array}$ \\
\hline D11 & $\begin{array}{l}\text { She [ESN] is very compassionate with them [patients and family]. (MDT } \\
\text { interview) }\end{array}$ \\
\hline D12 & $\begin{array}{l}\text { I actually have never mastered the art of doing a very streamlined literature } \\
\text { search and need more skills in the quant [statistics] side.(ANPc Interview) }\end{array}$ \\
\hline D13 & $\begin{array}{l}\text { There is a certain element of fear as well [among nurses about the ANP role], } \\
\text { you know that's a huge responsibility...to take on...to diagnose epilepsy, and to } \\
\text { decide on treatments,... use the information... what if I made a mess of } \\
\text { something?... [that has] serious implications for patients...That's a big } \\
\text { responsibility to take on board so there is fear... (MDT interview) }\end{array}$ \\
\hline D14 & $\begin{array}{l}\text { They [other nurses] say 'I'm not going down that road, absolutely not'..., } \\
\text { because candidate ANPS, they're very out on their own [autonomous] and it is } \\
\text { very stressful. (ANPc interview) }\end{array}$ \\
\hline \multicolumn{2}{|c|}{ Domain E: Implementation process } \\
\hline E1 & $\begin{array}{l}\text { I think we are at a critical point, I don't think we can stretch the services } \\
\text { provided by the nurses too much more...we are already struggling. ... the nurse } \\
\text { practitioners are working extremely hard,...they put a lot of energy into their } \\
\text { work..., which is fantastic but I don't think they can do much more... we are } \\
\text { actually at breaking point ... if you provide a good service you start becoming a } \\
\text { victim of your success, demand increases, expectations increase and we can't } \\
\text { stretch without more resources... but you also need to make sure there is } \\
\text { adequate medical supervision ... even though they [ESNs] provide great } \\
\text { services and do valuable clinical work, they still need to be mentored and } \\
\text { supervised... (Medical personnel interview) }\end{array}$ \\
\hline E2 & $\begin{array}{l}\text { Our cohort of patients is growing all the time, staff levels aren't growing with } \\
\text { the cohort of patients. Yeah and the thing is at the end of the day ... the nurses' } \\
\text { [role] have expanded over the last } 2 \text { years greatly. You can see that in the } \\
\text { statistics, the amount of patients, the data, you can see our cohorts are getting } \\
\text { bigger, and bigger, and bigger but our staffing levels aren't. (Allied health } \\
\text { professional interview) }\end{array}$ \\
\hline
\end{tabular}




\begin{tabular}{|l|l|}
\hline E3 & $\begin{array}{l}\text { The concern I would have is that, ultimately people will tip over the edge when } \\
\text { they've done too much and they've taken on far too much... there's a burnout } \\
\text { risk there. (DoN interview) }\end{array}$ \\
\hline E4 & $\begin{array}{l}\text { One concern is that the [ESNs] are so good at this [developing services] they } \\
\text { will try and spread themselves too thinly and therefore the quality of the } \\
\text { service, or their own personal well-being, will suffer because they are trying to } \\
\text { do too much. (Medical personnel interview) }\end{array}$ \\
\hline E5 & $\begin{array}{l}\text { The case load is huge. We have not developed satellite clinics because we felt } \\
\text { are we just doing too much, are we out growing our supply. (Medical personnel } \\
\text { interview) }\end{array}$ \\
\hline $\begin{array}{l}\text { E6re is nobody, or no group of people to take a kind of a longer view into that } \\
\text { [future vision]... looking at have you got the tools to do your job? the number } \\
\text { of patient encounters doesn't give me a measure of how successful the service } \\
\text { is, ...it's about quality more than quantity.(Allied health professional interview) }\end{array}$ \\
$\begin{array}{l}\text { I was looking at figures today... and you look at the outpatient activity alone } \\
\text { and it's just skyrocketed over the last couple of years...I suppose the question is } \\
\text { well, how are you going to enable all of that work into the future and who has } \\
\text { time for planning. (DoN interview) } \\
\text { E7 } \\
\text { He [names consultant] was very effective in that way[prescribing medication] } \\
\text { and I guess that's why I like seeing him, maybe because he can tell me more } \\
\text { about medications and I trust him maybe. (PWE) }\end{array}$ \\
$\begin{array}{l}\text { I'm a real cynic, the reason that they want more nurse specialists is } \\
\text { because...the cut backs [reduction in funding] ... why have a doctor when you } \\
\text { can put in a nurse? (PWE) }\end{array}$ \\
\hline E9
\end{tabular}

